\title{
PREFACE
}

\section{A Tribute to Eberhard F. Mammen, M.D. (1930-2008)}

Welcome to a very special issue of Seminars in Thrombosis and Hemostasis. This issue marks the end of another year and also represents the last issue of Seminars in Thrombosis and Hemostasis to carry the name of the founding editor, Eberhard F. Mammen, as the editor in chief. As recently announced in a previous issue of Seminars in Thrombosis and Hemostasis, Eberhard passed away on July 1 of this year. ${ }^{1,2}$ As also announced several times in the past, Eberhard was not only the founding editor but also acted in the capacity of editor in chief of this journal for the past 34 years. ${ }^{2,3}$ It is fitting, then, that we celebrate the life of this man whom we came to know as mentor and friend. Accordingly, this particular issue of Seminars in Thrombosis and Hemostasis has been crafted by the editors of this journal as a tribute to Eberhard F. Mammen and stands as a testament to the breadth of his career and the extent of his influence in the field of thrombosis and hemostasis. The articles within this issue are indeed a fine tribute to Eberhard, but each article can also be viewed as a state-of-the-art review on the topic of specific interest.

As an acknowledgment of Eberhard's contribution to the field of thrombosis and hemostasis in general, and to this journal in particular, the publisher, Thieme Medical Publishers, would also like to announce the creation of the Eberhard F. Mammen Excellence in Thrombosis and Hemostasis Awards. Thus, beginning in 2009, Seminars in Thrombosis and Hemostasis will begin a series of annual awards in recognition of excellence in the field of thrombosis and hemostasis. There will be two categories of awards; namely, "Most popular article awards" and "Young investigator awards." Specific details are available elsewhere in this issue. ${ }^{4}$

We begin this special collation issue with the poignant eulogy by Ananda Prasad and Hau Kwaan and the personal tributes from Houria Hassouna and John Penner. Not only was Eberhard the founding editor and ongoing editor in chief of Seminars in Thrombosis and Hemostasis, but also he was essentially responsible for selecting its content and shaping the journal over the past three decades. Over a span of five decades, Eberhard published more than 300 articles on various topics in thrombosis and hemostasis. Over the past three decades, quite a few of these articles were published in Seminars in
Thrombosis and Hemostasis. A brief review of Eberhard's written contributions to this field and inclusive of Seminars in Thrombosis and Hemostasis has also recently been highlighted. ${ }^{5}$ Indeed, four of his top five most popular articles (as evidenced by citation data) were published in this journal. ${ }^{5}$

Prasad and Kwaan recount the story of one particular publication from Eberhard's early career; namely, that to do with discovery of Fibrinogen Detroit. ${ }^{6,7}$ A true scientist, Eberhard used fibrinogen obtained from his own blood as the control for a series of studies that ultimately culminated in the characterization of Fibrinogen Detroit and the first demonstration of a molecular defect in an abnormal fibrinogen. ${ }^{6,7}$ One of the more interesting observations made by people who knew Eberhard was the extent of his interest and the breadth of his work. As noted by Prasad and Kwaan, Eberhard was a member of various departments within his institution, including Obstetrics and Gynecology, Physiology and Pharmacology, Pathology, and Surgery. But his first and true research love was blood coagulation. Mentored by the pioneer on mechanisms of coagulation, Walter Seegers, Eberhard engaged in extensive studies in a wide variety of disorders of hemostasis. His published works cover both basic investigations of clotting proteins and the scientific basis of clinical complications ranging from disseminated intravascular coagulation to thrombosis in preeclampsia.

We begin the collation of tribute articles with that prepared by one of the regional editors of Seminars in Thrombosis and Hemostasis who is the guest editor for this particular issue: a review of the clinical utility of the PFA-100. This instrument (a platelet function analyzer) is a relatively new tool for the investigation of "primary hemostasis" and was first introduced to us in 1995 in an issue of Seminars in Thrombosis and Hemostasis that included data from a field trial headed by Dr. Eberhard Mammen. ${ }^{8}$ Since that time, the PFA-100 has featured in nearly 500 publications and some 35 reviews, including another article by Eberhard in this journal. ${ }^{9}$ It is interesting to note that both these two articles by Eberhard $^{8,9}$ appear in his top 10 cited articles listing ${ }^{5}$ as well as his top 10 cited articles published in Seminars in Thrombosis and Hemostasis. ${ }^{4}$

\footnotetext{
${ }^{1}$ Department of Haematology, Institute of Clinical Pathology and Medical Research (ICPMR), Westmead Hospital, WSAHS, Westmead, NSW, Australia.

A Tribute to Eberhard F. Mammen, M.D. (1930-2008); Guest Editor, Emmanuel J. Favaloro, Ph.D., M.A.I.M.S.
}

Semin Thromb Hemost 2008;34:703-708. Copyright (C) 2008 by Thieme Medical Publishers, Inc., 333 Seventh Avenue, New York, NY 10001, USA. Tel: +1(212) 584-4662.

DOI 10.1055/s-0029-1145252. ISSN 0094-6176. 
The current article by Favaloro reviews the history of the PFA-100 and details its clinical utility in several settings. This is not the first review of the PFA- 100 by this author, nor his first such review to appear in this journal, ${ }^{10,11}$ but it is his most comprehensive to date. As previously reported by Favaloro in this journal, ${ }^{10}$ the PFA-100 has potential utility in monitoring antiplatelet therapy (including aspirin) and as a screening tool for investigating possible von Willebrand disease (VWD) and various platelet disorders. The PFA-100 also has potential value for monitoring DDAVP (desmopressin) therapy in both $\mathrm{VWD}^{11}$ and functional platelet disorders. However, the most recent attention within the literature has focused on sensitivity to antiplatelet medication, where a new language has also emerged, with researchers talking about "aspirin resistance," "aspirin responsiveness," and "aspirin nonresponsiveness." Ultimately, the greatest strengths of the PFA-100 are its simplicity in use and excellent sensitivity to various hemostatic disturbances. However, because it is a "global" test system for primary hemostasis, this also creates a significant limitation because the PFA-100 is not specific for, nor predictive of, any particular disorder. However, used appropriately, the PFA-100 can be considered a worthwhile addition to hemostasis laboratories involved in the identification or therapeutic monitoring of primary hemostatic disorders. The potential future applications for this simple instrument are also briefly assessed. Perhaps it is fitting to end this particular article where it begins and to allow Eberhard to have the last word. In closing his 1998 article in Seminars in Thrombosis and Hemostasis, ${ }^{9}$ he identified the PFA-100 as "an excellent test system to assess platelet-related primary hemostasis with high accuracy and reliability ..." that ". . . may be effectively utilized as a routine test to detect abnormal platelet function ..." and further that "the ease with which the PFA-100 system can be operated makes it an excellent tool to screen for plateletrelated primary hemostasis defects." But perhaps even Eberhard could not predict how far the interest in the PFA-100 would grow.

The second article is from Kristen Snyder and another of the regional editors of Seminars in Thrombosis and Hemostasis, Craig Kessler, and covers the association of cancer and thrombosis, an association that has been known for nearly 150 years. Compared with patients without cancer, those with cancer have an increased risk of thrombosis and recurrent thrombosis. Patients with idiopathic venous thromboembolism are also at increased risk of later being diagnosed with cancer. Although the mechanisms of the association of cancer and thrombosis are still being investigated, much of the recent work points to an influence of thrombin on cancer biology. This article therefore focuses on the important role of thrombin in cancer research, as well as on recent in vitro work illustrating the mechanisms by which thrombin may affect cancer angiogenesis, cell invasion, and enhanced tumor metastasis, and also covers clinical trials investigating the potential role of antithrombotics in cancer incidence and survival.

Snyder and Kessler also remind us that Eberhard Mammen investigated the effects of thrombin and its role in cancer cell growth and the mechanisms of tumor metastasis in collaboration with others in the 1990s. ${ }^{12}$ Mammen and colleagues demonstrated that tumor cell adhesion was dependent on the action of the native form of thrombin, alpha-thrombin. Their observations provided important insights into the mechanisms of cancer development and greatly contributed to current knowledge of the relationship between hemostasis and malignancy.

The third article is contributed by another regional editor of Seminars in Thrombosis and Hemostasis, Marcel Levi, and colleagues on the topic of sepsis, coagulation, and antithrombin. This is another area of work that features significantly in Eberhard's publications, including several of his most highly cited articles. $^{4,5}$ Indeed, Eberhard was one of the first to identify the importance of the coagulation inhibitor we call antithrombin and the potential for antithrombin replacement in patients with severe sepsis. ${ }^{13,14}$ As explained by Levi and colleagues, current insights in the pathogenesis of multiple organ dysfunction in patients with sepsis point to a pivotal role of inflammation and coagulation. One of the most important mechanisms contributing to the activation of coagulation in sepsis is the downregulation of physiologic anticoagulant systems, such as the antithrombin pathway. Eberhard hypothesized that coagulation activation and antithrombin were important factors in patients with sepsis as early as 20 years ago. Abundant experimental and clinical studies have supported that notion in recent years. The better understanding of the pathogenesis of coagulation activation and the role of natural anticoagulants in sepsis has led to the development of anticoagulant factor concentrates, such as antithrombin concentrate. Clinical studies indicate that these interventions may have a role in the (supportive) treatment of patients with sepsis, mostly based on surrogate outcomes, but ongoing studies will have to confirm a beneficial effect in reducing mortality. Like the case for Favaloro and the PFA100 , this is not the first such review by Levi for this journal, and a related review on the role of natural anticoagulants in the pathogenesis and management of systemic activation of coagulation and inflammation in critically ill patients was recently published by Levi and van der Poll in Seminars in Thrombosis and Hemostasis. ${ }^{15}$

The next article is by Lippi and Franchini and concerns the pathogenesis of venous thromboembolism. A comprehensive understanding of the pathogenesis of venous thrombosis is essential for identifying patients at increased risk and who may therefore benefit from more 
aggressive preventive and therapeutic measures. As for other pathologies, the pathogenesis of venous thromboembolism is multifactorial. All risk factors, either congenital or acquired, are relatively "innocent" when considered alone. However, when an individual is unlucky enough to inherit one or more abnormalities, compounded in many cases by environmental hazards, that person may be propelled over a threshold that precipitates the development of thrombosis. Lippi and Franchini use the analogy here of "the last drop makes the cup run over."

A reinterpretation of the traditional Virchow's triad (abnormal vessel wall, abnormal blood flow, and abnormal blood constituents) was provided by Eberhard Mammen and included within a seminal and highly cited review published in $1992,{ }^{5,16}$ wherein he concluded that at least two of these three postulated factors in combination were important in the development of a venous thrombosis, although decreased blood flow or "blood stasis" appeared to be the dominant component. The subsequent accumulation of blood within the intramuscular sinuses, especially of the calf, triggered hypercoagulability due to local accumulation of activated clotting factors and coagulation activation products and the simultaneous consumption of blood coagulation inhibitors. On Mammen's "hit list" nearly 20 years ago was included (among inherited abnormalities) decreased protein $\mathrm{C}$, protein $\mathrm{S}$, antithrombin III, plasminogen, and tissue plasminogen activator, and increased plasminogen activator inhibitor-1, whereas surgery, trauma, previous thromboembolism, prolonged immobility and paralysis, malignancy, congestive heart failure, obesity, advanced age, pregnancy and puerperium, varicose veins, and oral contraceptives were also identified among acquired predisposing conditions. Some two decades later, the situation has perhaps not changed so much, although studies continue to expand our knowledge of this topic, clarifying the relative contribution of each single risk factor in the pathogenesis of venous thrombosis.

The next article, by Meijer and Schulman, is on determinants of bleeding risk in patients on antithrombotic and antifibrinolytic drugs. The risk of bleeding associated with antithrombotic and fibrinolytic therapy depends on factors that are specific for the drugs and the patients. In this narrative review, Meijer and Schulman describe the most important risk factors for bleeding for each class of drugs. Pertinent examples are recent initiation of therapy with vitamin $\mathrm{K}$ antagonists, lowmolecular-weight heparins and renal dysfunction, and higher dose of aspirin. However, for every class of drug there are also examples that are more controversial. Knowledge of these risk factors helps to weigh the risk and benefit in the selection of therapy in individual patients. Moreover, some risk factors can be modified or avoided if they are recognized. This article is a fitting tribute to Eberhard, given that early in his career, and long before the large trials in stroke and myocardial infarction, he wrote about the therapeutic possibilities of thrombolytic agents and their risk of causing bleeding. ${ }^{17}$ Some 24 years later, and some 22 years ago, Eberhard participated in a study addressing the timing of heparin administration in patients treated with streptokinase for acute myocardial infarction. ${ }^{18}$ Later still, a few more reviews on anticoagulant therapy were also forthcoming. ${ }^{19,20}$ This illustrates the length of Eberhard's career.

The next article is by Wada, Usui, and Sakuragawa and addresses hemostatic abnormalities in liver disease. As explained by Wada and colleagues, Eberhard contributed greatly to the understanding of the relationship between hemostatic abnormalities and liver diseases. ${ }^{21-}$ ${ }^{24}$ The physiology of the hemostatic system is closely linked to liver function because the liver parenchymal cells produce most of the factors of the clotting and fibrinolytic systems. Acute or chronic hepatocellular diseases and hepatic failure including liver cirrhosis, vitamin $\mathrm{K}$ deficiency, liver surgery including liver transplantation, and sclerotherapy of bleeding esophageal varices show various hemostatic abnormalities in the coagulation system, fibrinolytic system, platelets, and reticuloendothelial system. Hemostatic abnormalities in patients with hepatic failure or those that have undergone liver surgery are similar to those in disseminated intravascular coagulation.

The next article is contributed by Job Harenberg, a long-time colleague of Eberhard Mammen, and is on the topic of new anticoagulants. Eberhard Mammen's own work related to anticoagulant therapy stretches back to the mid-20th century, where he identified the inhibition of coagulation factor 3 through anticoagulants such as heparin. ${ }^{25}$ Soon thereafter, he described the benefit of anticoagulation of blood in hemodialysis patients with heparin. ${ }^{26}$ At the beginning of the low-molecularweight heparin era, he investigated the pharmacodynamics and clinical properties of low-molecular-weight heparin. ${ }^{19,20,27} \mathrm{He}$ identified the reduced incidence of heparin-induced thrombocytopenia as one of the main advantages over conventional heparins.

As also explained by Harenberg, anticoagulant drugs are now the most frequently hospital-prescribed compounds in many countries and are used with the intention to prevent and treat venous and arterial thromboembolism. However, the occasional but significant side effects and the necessity of dose adjustment for both the unfractionated heparins and coumarins have led to the development of low-molecular-weight heparins, heparinoids, and direct thrombin inhibitors. Again, due to the limitations also of these anticoagulants, synthetic indirect and direct factor $\mathrm{Xa}$ inhibitors and direct thrombin inhibitors have been further developed with the aim to improve the benefit/risk ratio for anticoagulant therapy of patients using a simplified mode of 
action. The overview by Harenberg describes the results of some recent studies of these inhibitors of blood coagulation. This author has also contributed many past articles to this journal, stretching back many years, but also including a quite recent article with coauthor Wehling. ${ }^{28}$

The final tribute article within this issue of Seminars in Thrombosis and Hemostasis, by Heilmann and colleagues on the topic of antiphospholipid antibodies (aPL) in pregnancy, is dedicated to the memory of both Eberhard Mammen and another colleague of this group and of Eberhard, namely Rodger Bick, who also recently passed away in 2008. Both Eberhard Mammen and Rodger Bick had a strong interest in the diagnosis and management of antiphospholipid syndrome (APS) in pregnant women. They covered this topic together in many educational workshops and provided authoritative accounts of this syndrome at these and other forums. Through their effort, there was an increased awareness and development of standard-of-care approaches around the globe. The authors of this article were strongly influenced by their teachings, and the current work has arisen from their leadership and direction.

APS represents a major risk factor in pregnancy and results in several serious complications including fetal loss. ${ }^{29-31}$ In this dedicated report, Heilmann and colleagues describe their experience in the treatment of pregnancies in patients with APS. They analyzed retrospective data from 140 pregnant women where the treatment results of 121 patients were recorded and studied two groups of patients receiving different treatment. The first group received the standard therapy with low-weight-molecular heparin and aspirin, and the second group also received intravenous immunoglobulin. Outcomes for live births were similar in both groups $(78 \%$ and $84 \%$ in the first and second groups, respectively), as was the abortion rate $(10.2 \%$ vs. $11.6 \%$, respectively). The late complication rate was lower in the second group $(5.8 \%$ vs. $12.8 \%$ in the first [standard therapy] group, $p<0.05)$. They also found a trend to higher percentage of natural killer cells in patients with pregnancy complications. In summary, their retrospective data showed an improvement of late pregnancy complications by additional use of intravenous immunoglobulin. They hypothesize that intravenous immunoglobulin may influence higher natural killer cell activity in patients with previous pregnancy complications.

Finally, at the end of this tribute issue, we have republished six of Eberhard's most popular articles from Seminars in Thrombosis and Hemostasis. These were specifically selected from the list of his 10 most popular articles $^{4}$ to showcase the breadth of Eberhard's influence in the field of thrombosis and hemostasis. I do not think there is much more for me to add here, except to say in final passing, "Eberhard, this issue is your tribute. We were honored to know you and to count you as friend and mentor."

My heartfelt thanks to all who were able to participate in the preparation of this special issue.

$$
\begin{array}{r}
\text { Emmanuel J. Favaloro, Ph.D., M.A.I.M.S. }{ }^{1} \\
\text { Guest Editor }
\end{array}
$$

\section{REFERENCES}

1. Schiff D. Eulogy. Eberhard Mammen, M.D. 1930-2008. Semin Thromb Hemost 2008;34:305

2. Favaloro EJ. Editorial. Semin Thromb Hemost 2008;34:307

3. Schiff D, Burgess T. Editorial. Semin Thromb Hemost 2004; 30:601

4. Favaloro EJ, on behalf of the regional editors. Editorial. Semin Thromb Hemost 2008;34:693-696

5. Favaloro EJ. Measuring the quality of journals and journal articles: the impact factor tells but a portion of the story. Semin Thromb Hemost 2008;34:7-25

6. Mammen EF, Prasad AS. [Familial dysfibrinogenemia“Detroit fibrinogen."]. Verh Dtsch Ges Inn Med 1968;74: 140-144

7. Blomback M, Blomback B, Mammen EF, Prasad AS. Fibrinogen Detroit-a molecular defect in the N-terminal disulphide knot of human fibrinogen? Nature 1968;218: 134-137

8. Mammen EF, Alshameeri RS, Comp PC. Preliminary data from a field trial of the PFA-100 system. Semin Thromb Hemost 1995;21(Suppl 2):113-121

9. Mammen EF, Comp PC, Gosselin R, et al. PFA-100 system: a new method for assessment of platelet dysfunction. Semin Thromb Hemost 1998;24:195-202

10. Favaloro EJ. The utility of the PFA-100 in identification of von Willebrand disease: a concise review. Semin Thromb Hemost 2006;32:537-545

11. Favaloro EJ. Laboratory monitoring of therapy in von Willebrand disease: efficacy of the PFA $-100^{\circledR}$ and VWF:CB as coupled strategies. Semin Thromb Hemost 2006;6:566576

12. Wojtukiewicz MZ, Tang DG, Ciarelli JJ, et al. Thrombin increases the metastatic potential of tumor cells. Int J Cancer 1993;54:793-806

13. Balk R, Emerson T, Fourrier F, et al. Therapeutic use of antithrombin concentrate in sepsis. Semin Thromb Hemost 1998;24:183-194

14. Mammen EF. Antithrombin: its physiological importance and role in DIC. Semin Thromb Hemost 1998;24:19-25

15. Levi M, van der Poll T. The role of natural anticoagulants in the pathogenesis and management of systemic activation of coagulation and inflammation in critically ill patients. Semin Thromb Hemost 2008;34:459-468

16. Mammen EF. Pathogenesis of venous thrombosis. Chest 1992;102(6, Suppl):640S-644S

17. Mammen E. El tratamiento de las tromboembolias. Folia Clin Int (Barc) 1962;12:146-154

18. Timmis GC, Mammen EF, Ramos RG, et al. Hemorrhage vs rethrombosis after thrombolysis for acute myocardial infarction. Arch Intern Med 1986;146:667-672

19. Mammen EF. Why low molecular weight heparin? Semin Thromb Hemost 1990;16(Suppl):1-4 
20. Mammen EF, Arcelus J, Messmore H, Altman R, Nurmohamed M, Eldor A. Clinical differentiation of low molecular weight heparins. Semin Thromb Hemost 1999;25(Suppl 3): 135-144

21. Mammen EF. Coagulopathies of liver disease. Clin Lab Med 1994;14:769-780

22. Mammen EF. Coagulation defects in liver disease. Med Clin North Am 1994;78:545-554

23. Mammen EF. Coagulation abnormalities in liver disease. Hematol Oncol Clin North Am 1992;6:1247-1257

24. Mammen EF. Blood coagulation disorders in liver diseases. Dtsch Med Wochenschr 1970;95:2241-2242

25. Beller FK, Mammen E. Studies on a third plasma factor in thromboplastin formation. Klin Wochenschr 1955;33:155-156

26. Nieth H, Mammen E, Gross R. Heparinization of blood in extracorporeal hemodialysis. Klin Wochenschr 1958;36: $372-376$
27. Troy S, Fruncillo R, Ozawa T, Mammen E, Holloway S, Chiang S. The dose proportionality of the pharmacokinetics of ardeparin, a low molecular weight heparin, in healthy volunteers. J Clin Pharmacol 1995;35:1194-1199

28. Harenberg J, Wehling M. Current and future prospects for anticoagulant therapy: inhibitors of factor $\mathrm{Xa}$ and factor IIa. Semin Thromb Hemost 2008;34:39-57

29. Wong RCW, Favaloro EJ. Clinical features, diagnosis, and management of the antiphospholipid syndrome. Semin Thromb Hemost 2008;34:295-304

30. Pierangeli SS, Chen PP, Raschi E, et al. Antiphospholipid antibodies and the antiphospholipid syndrome: pathogenic mechanisms. Semin Thromb Hemost 2008;34:236-250

31. Tincani A, Bazzani C, Zingarelli S, Lojacono A. Lupus and the antiphospholipid syndrome in pregnancy and obstetrics: clinical characteristics, diagnosis, pathogenesis, and treatment. Semin Thromb Hemost 2008;34:267-273 